\title{
A reconstruction of annual mass balances of Austria's glaciers from 1969 to 1998
}

\author{
J. ABERMANN, ${ }^{1,2}$ M. KUHN, ${ }^{1,2}$ A. FISCHER ${ }^{2}$ \\ ${ }^{1}$ Commission for Geophysical Research, Austrian Academy of Sciences, Dr-Ignaz-Seipel-Platz 2, A-1010 Vienna, Austria \\ E-mail: jakob.abermann@uibk.ac.at \\ ${ }^{2}$ Institute of Meteorology and Geophysics, University of Innsbruck, Innrain 52, A-6020, Innsbruck, Austria
}

\begin{abstract}
Annual glacier mass balances are reconstructed for $96 \%$ of the Austrian glacier-covered area $\left(451\right.$ of $\left.470 \mathrm{~km}^{2}\right)$ between 1969 and 1998 . The volume change derived from two complete glacier inventories (1969 and 1998) serves as the boundary condition that is aimed to be reproduced. ERA-40 reanalysis data as well as a gridded precipitation dataset (HISTALP) are used to drive a positive degreeday (PDD) model. The results are verified with four independent long-term mass-balance series. The spatial and vertical distribution of the tuning parameters is altered in order to reproduce the measured mean annual surface mass balances of selected glaciers, and a strong correlation is found between the median elevation of a glacier and the degree-day factor (DDF) at this elevation. This result implies that the lower a glacier's median elevation is, the less melt occurs at a given elevation and temperature. We attribute this to the fact that lower-altitude glaciers are generally those with more accumulation, which leads to later exposure of bare ice and a longer period of high-albedo snow cover. A further improvement of the model was achieved by making DDF a function of time as well as space. The results indicate that mean DDFs generally increase for a given date over a sequence of consecutive negative mass-balance years, which probably reflects the reduction in albedo related to that. Finally, the major drivers of the observed mass-balance evolution are investigated: summer PDD sums correlate significantly better with the observed mass-balance changes than annual PDD sums or precipitation do. This implies that annual mass balances in the study area are governed by summer temperatures.
\end{abstract}

\section{INTRODUCTION}

Mountain glaciers contribute considerably to observed and predicted sea-level rise (e.g. Kaser and others, 2006; Lemke and others, 2007; Meier and others, 2007). In order to estimate this contribution, it is crucial to know glacier mass balances. Mass-balance measurements are restricted to few glaciers worldwide, in total around 250 (Dyurgerov and Meier, 2005), and only about 85 data series last longer than 10 years (Braithwaite, 2002). Most glaciers for which mass balances are measured are chosen for accessibility or by coincidence. However, they might not be representative of the mass balances of all glaciers in a given catchment or mountain range, and simple extrapolation to other glaciers is known to be unreliable (Fountain and others, 2009).

Different methods have been used to model the total glacier mass balance of mountain ranges. Machguth and others (2009) used output from regional climate models (RCMs) to run an energy-balance model for all Swiss glaciers, and Schöner and Böhm (2007) applied a statistical approach to model the mass balance of a sample of Austria's glaciers as far back as the glacier maximum of the Little Ice Age. Hock and others (2009) estimate the world's glaciers' total contribution to sea-level rise. It has also been shown that reanalysis data can be used successfully to reconstruct the mass-balance history of individual glaciers (e.g. Radić and Hock, 2006; Rasmussen and Wenger, 2009).

The annual surface mass balance of 761 Austrian glaciers is reconstructed for all years between 1969 and 1998, which is an important input for run-off modelling on a catchment or larger scale. A positive degree-day (PDD) model is applied, and its performance validated. Although PDD models are generally viewed as crude because they do not resolve energy-balance terms explicitly, it has been shown in the literature that their performance is comparable to energy-balance models (Hock, 2003). The scale of the study area, and the computational simplicity required to apply the model to a large number of glaciers over a 30 year timespan, was one reason for choosing a simple approach. Furthermore, the main task is to describe measured volume changes with higher temporal resolution which can be reliably achieved with such a model. However, it is shown that it is necessary to use temporally and spatially varying degree-day factors (DDFs). In order to reproduce directly measured volume changes and their variations, one needs annual resolution, i.e. mean annual DDFs for each elevation band. While the stepwise change from low DDFs of snow and firn to the high DDFs of bare ice moves up-glacier during the season, the annual mean of $\operatorname{DDF}(h)$ with altitude becomes a smooth profile which is approached by a linear function of elevation in this study.

The generalizability of directly measured mass balances is addressed, and the relative importance of the main meteorological factors (temperature, precipitation) that control each year's mass balance is investigated.

\section{STUDY AREA}

The study area is the Austrian part of the eastern Alps $\left(46^{\circ} 40^{\prime}-47^{\circ} 35^{\prime} \mathrm{N}, 9^{\circ} 50^{\prime}-13^{\circ} 40^{\prime} \mathrm{E}\right)$ where, in 1998, 910 glaciers covered a total area of $470 \mathrm{~km}^{2}$ (Lambrecht and Kuhn, 2007; Kuhn and others, 2009). Figure 1 shows a map with the 1998 glacier extent and an Advanced Spaceborne Thermal Emission and Reflection Radiometer (ASTER) digital elevation model (DEM) of elevations higher than $2000 \mathrm{~m}$ in greyscale. The ASTER DEM is used for illustrative purposes only; our analysis was performed with photogrammetrically 


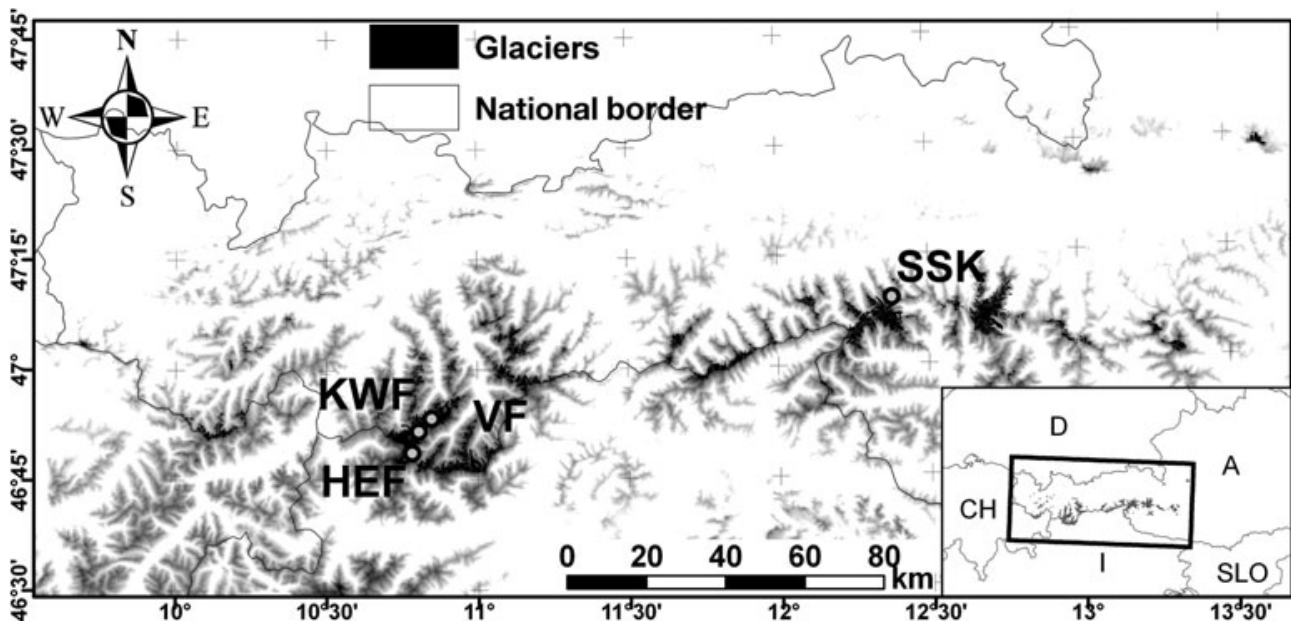

Fig. 1. Glacier cover in Austria according to the glacier inventory of 1998 (Lambrecht and Kuhn, 2007). The glaciers HEF, KWF, VF and SSK are marked. Elevations higher than $2000 \mathrm{~m}$, derived from an ASTER DEM, are displayed in greyscale in the background.

derived DEMs (see section 3). Mass balances have been measured over the entire modeled time-span on four glaciers only: Hintereisferner (HEF), Kesselwandferner (KWF), Vernagtferner (VF) and Stubacher Sonnblickkees (SSK) (Schöner and Böhm, 2007). These glaciers' mass-balance series are used to validate the model; their locations are shown in Figure 1 and basic glaciological parameters are provided in Table 1. More information on the distribution of Austria's glaciers and its relationship to climate can be found in Abermann and others (2009).

\section{DATA}

\subsection{Glaciological data}

Two glacier inventories serve as glaciological input data for this study. Both were produced by aerial photogrammetry including glacier boundaries and DEMs (e.g. Gross, 1987; Lambrecht and Kuhn, 2007). Glacier area changes, which are necessary to compute annual surface mass balances, are approximated by assuming that the initial area (1969) remains constant until 1985 and then interpolating linearly to the final glacier area (1998). This pattern of area change does not account for glacier growth in the late 1970s and early 1980 s but is similar to the mean glacier area changes of the study period (Abermann and others, 2009).

Volume change, $\Delta V$, is calculated by subtracting the 1998 DEMs from the 1969 glacier extent. The total balance,

Table 1. Basic glaciological parameters for the glaciers used to validate the model: area, minimum elevation $\left(z_{\min }\right)$, maximum elevation $\left(z_{\max }\right)$, median elevation $\left(z_{\mathrm{med}}\right)$, main aspect of the ablation area, latitude and longitude as given in Lambrecht and Kuhn (2007) and Kuhn and others (2009) for 1998

\begin{tabular}{lccccccc}
\hline Glacier & $\begin{array}{c}\text { Area } \\
\mathrm{km}^{2}\end{array}$ & $\begin{array}{c}Z_{\min } \\
\mathrm{m}\end{array}$ & $\begin{array}{c}Z_{\max } \\
\mathrm{m}\end{array}$ & $\begin{array}{c}Z_{\text {med }} \\
\mathrm{m}\end{array}$ & Aspect & Lat. (N) & Long. (E) \\
& & & & & & & \\
\hline $\mathrm{HEF}$ & 8.4 & 2400 & 3710 & 2990 & $\mathrm{NE}$ & $46^{\circ} 48^{\prime}$ & $10^{\circ} 46^{\prime}$ \\
KWF & 4.2 & 2690 & 3500 & 3140 & $\mathrm{SE}$ & $46^{\circ} 51^{\prime}$ & $10^{\circ} 48^{\prime}$ \\
VF & 8.8 & 2760 & 3630 & 3080 & $\mathrm{SE}$ & $46^{\circ} 53^{\prime}$ & $10^{\circ} 49^{\prime}$ \\
SSK & 1.5 & 2490 & 3030 & 2760 & $\mathrm{E}$ & $47^{\circ} 08^{\prime}$ & $12^{\circ} 36^{\prime}$
\end{tabular}

$B$, was calculated by

$$
B=\Delta V_{1969-98} \rho \quad\left[\mathrm{kg} \text { or } 10^{-3} \mathrm{~m}^{3} \text { w.e. }\right] .
$$

The whole volume change is assumed to have occurred as loss of ice with a density of $900 \mathrm{~kg} \mathrm{~m}^{-3}$. The resulting $B$ has thus to be taken as the upper bound of the actual mass loss, as some unknown fraction of the total volume change was lost as snow instead of ice. This uncertainty is discussed in section 6.

Directly measured mass-balance data of four glaciers spanning the entire investigation period (Table 1) were used to validate the model. Three of the glaciers are situated very close to each other in the Ötztal valley: HEF, KWF (Hoinkes and Lang, 1962; Kuhn and others, 1985, 1999; Fischer and Markl, 2008; Fischer, 2010) and VF (Reinwarth and EscherVetter, 1999; Escher-Vetter and others, 2009). SSK (Slupetzky, 1989, 2003; WGMS, 2007) is located in the Hohe Tauern and thus in a somewhat different climate (generally more precipitation; Abermann and others, 2011).

\subsection{Meteorological data}

The model uses temperature, $T$, equivalent-potential temperature, $\theta_{\mathrm{e}}$ and geopotential, $\Phi$, and precipitation as meteorological inputs. $T, \theta_{\mathrm{e}}$ and $\Phi$ and precipitation are taken from the European Centre for Medium-Range Weather Forecasts (ECMWF) ERA-40 reanalysis project (Uppala and others, 2005). T, $\theta_{\mathrm{e}}$ and $\Phi$ are taken from the 600, 700 and $850 \mathrm{hPa}$ level; precipitation data are the 6 hour forecast from the total precipitation field at the surface. The ERA-40 reanalysis dataset is a dynamically consistent, three-dimensional, gridded dataset with a resolution of $1.25^{\circ}$ that combines meteorological and satellite observations with a numerical weather-forecast model and covers the period 1957-2002.

The monthly Alps-wide precipitation dataset of the HISTALP project has a spatial resolution of $10^{\prime}$ of arc and includes homogenized weather-station data (Efthymiadis and others, 2006). The dataset was generated with data from valley stations only (Auer and others, 2005) due to well-known problems of precipitation measurement at high altitudes (e.g. Frei and Schär, 1998). It therefore does not account for an increase in precipitation with altitude and underestimates high-altitude precipitation. 
Generally, precipitation anomalies have the same sign at high- and at low-altitude stations (Auer and others, 2005; Böhm and others, 2008). In order to account for the increase in precipitation with elevation, $12 \mathrm{~mm}(100 \mathrm{~m})^{-1}$ were added to each month's precipitation sum up to a maximum elevation of $3300 \mathrm{~m}$, above which this value is assumed to remain constant. This vertical gradient is larger than annual gradients given by Kuhn and others (1982) and Kuhn (2003). Winter precipitation mainly consists of advective precipitation (unlike summer precipitation, where convection plays an important role); larger vertical gradients for winter precipitation are therefore expected for winter precipitation than for annual precipitation. Since accumulation is determined by winter precipitation, the chosen gradient best represented the observed vertical balance profile of selected glaciers.

HISTALP and ERA-40 precipitation are combined with the ERA-40 $\theta_{\mathrm{e}}$ to incorporate a spatially (HISTALP) and temporally (ERA-40) highly resolved precipitation dataset into the model. The higher-spatial-resolution HISTALP dataset is used to determine the total value for a month at a gridpoint and then split into 6 hourly time-steps given by the ERA-40 precipitation data and weighted accordingly. As an example, let HISTALP's total November precipitation at a glacier's gridpoint be $90 \mathrm{~mm}$ and let ERA-40 show that $30 \%$ of the month's precipitation fell on 6 November and $70 \%$ on 20 November. The monthly precipitation is then divided into two time-steps: $27 \mathrm{~mm}$ on 6 November and $63 \mathrm{~mm}$ on 20 November.

The rain-snow boundary is estimated by applying the regression function of Steinacker (1983) who related the rain-snow boundary empirically to the equivalent-potential temperature at $850 \mathrm{hPa}$. He found a relationship of the rainsnow boundary $z_{\mathrm{r} / \mathrm{s}}$ of

$$
z_{\mathrm{r} / \mathrm{s}}=\left(\frac{\theta_{\mathrm{e}}-12}{1.2}\right) \times 100,
$$

where the equivalent-potential temperature at $850 \mathrm{hPa}$ is inserted in ${ }^{\circ} \mathrm{C}$ (Steinacker, 1983). If, at a certain point in time, $\theta_{\mathrm{e}}$ at $850 \mathrm{hPa}$ is $42^{\circ} \mathrm{C}$ the rain-snow boundary is assumed to be at $2500 \mathrm{~m}$, applying Equation (2).

\section{THE MODEL}

A PDD model is applied as widely used in hydrological modelling (e.g. Hock, 2003, 2005; Kuhn, 2003; Huss and others, 2008 and references therein). To estimate the vertical temperature distribution at a certain point in time, temperatures at 600,700 and $850 \mathrm{hPa}$ and the geopotential there are used. All glacier-covered areas in the study area lie between these pressure levels at all points in time. The geopotential of a certain pressure level, $\Phi$, is converted into geopotential height, $z_{\mathrm{gp}}$, by applying

$$
z_{\mathrm{gp}} \approx \frac{\Phi}{\bar{g}} \quad[\mathrm{~m}],
$$

where $\bar{g}$ is the mean gravity acceleration $\left(9.81 \mathrm{~m} \mathrm{~s}^{-2}\right) . z_{\mathrm{gp}}$ is assumed to be equal to the geometrical height, $z$, with a satisfactory approximation (Stull, 2000).

If $z_{1}$ is located between the 700 and $850 \mathrm{hPa}$ levels, for instance, the temperature there, $T_{z 1}$, is

$$
T_{z 1}=\frac{T_{700}-T_{850}}{Z_{700}-Z_{850}}\left(z_{1}-z_{700}\right)+T_{700} \quad[K] .
$$

The same applies analogously for $z$ between 600 and $700 \mathrm{hPa}$.

To calculate ablation, the relation

$\mathrm{b}_{\mathrm{abl}}(x, y, z, t)=\operatorname{DDF}(x, y, z, t) T_{>0, \text { day }}(x, y, z, t) \quad$ [mm w.e. $]$

is used, where DDF is used for calibration and $T_{>0 \text {,day }}$ is the daily mean temperature above $0^{\circ} \mathrm{C}$.

Accumulation is estimated by

$b_{\text {acc }}(x, y, z, t)=P(x, y, z, t) R_{0 / 1}(x, y, z, t) \quad$ [mmw.e.],

where $P$ is precipitation and $R_{0 / 1}$ is a value that indicates whether the precipitation has fallen as snow or rain and that can only be 0 (rain) or 1 (snow). If $z<z_{\mathrm{r} / \mathrm{s} \text {, }}$ it is 0 , otherwise it is 1. Liquid precipitation is assumed not to contribute to glacier mass gain. Both ablation and accumulation are computed with a 6 hour time-step. Their sum gives the specific mass balance, $b$.

The spatial and vertical dependence of DDF is a crucial point in the model and needs explanation. In the following, the vertical dependence of DDF $(\mathrm{dDDF} / \mathrm{d} z)$ is introduced first, and then the spatial dependence.

An energy-balance model, SOMARS (Simulation Of glacier surface Mass balance And Related Sub-surface processes; Greuell and Konzelmann, 1994), was applied and validated with in situ measurements of the snow water equivalent at two locations on HEF by Schrott (2006). With the results of this model (specific balance) an ablation season's mean DDF at these two weather stations (2650 and $3050 \mathrm{~m}$ ) is calculated. DDF varies vertically by $-0.32 \mathrm{~mm}$ w.e. $(\mathrm{Kd})^{-1}$ per $100 \mathrm{~m}$ of elevation. Over a $1000 \mathrm{~m}$ height interval this amounts to a difference of $-3.2 \mathrm{~mm}(\mathrm{Kd})^{-1}$; for example, the lower end may have a DDF of $7.2 \mathrm{~mm}(\mathrm{Kd})^{-1}$ (low albedo) and the upper end one of $4 \mathrm{~mm}(\mathrm{Kd})^{-1}$ (high albedo). This vertical gradient of DDFs is extrapolated and used as the vertical dependence of DDF in the model. The vertically changing DDFs are in line with theoretical considerations by Hock (2003). On average over a melt season, the albedo of lower areas is smaller, so, for a given temperature, the energy added to a surface is higher, as more shortwave radiation is absorbed. This is independent of temperature and would therefore not be reflected in a temperature-index approach with a constant DDF for the whole glacier.

In addition to the vertically varying DDFs, a spatial dependence is introduced. This is found by running the model iteratively with $\mathrm{dDDF} / \mathrm{d} z$ as described above and with the condition that we must obtain the measured $B$ of each glacier as it had been previously calculated from the glacier inventories. Each individual glacier thus has its own set of DDFs that best represents the measured $B$. DDFs vary considerably among the individual glaciers and are discussed below.

\section{RESULTS}

The results of the first calibrated model run (run I) for HEF are shown in Figure $2 \mathrm{a}$. It should be noted that the area changes for the modelled balances are approximated as explained above, whereas the area changes for the measured balances are adjusted each year. This approximation is made so that the method may be applied to unmeasured glaciers as well. Statistical values in Table 2 indicate that a similar quality of results is achieved for the three other glaciers where cross- 

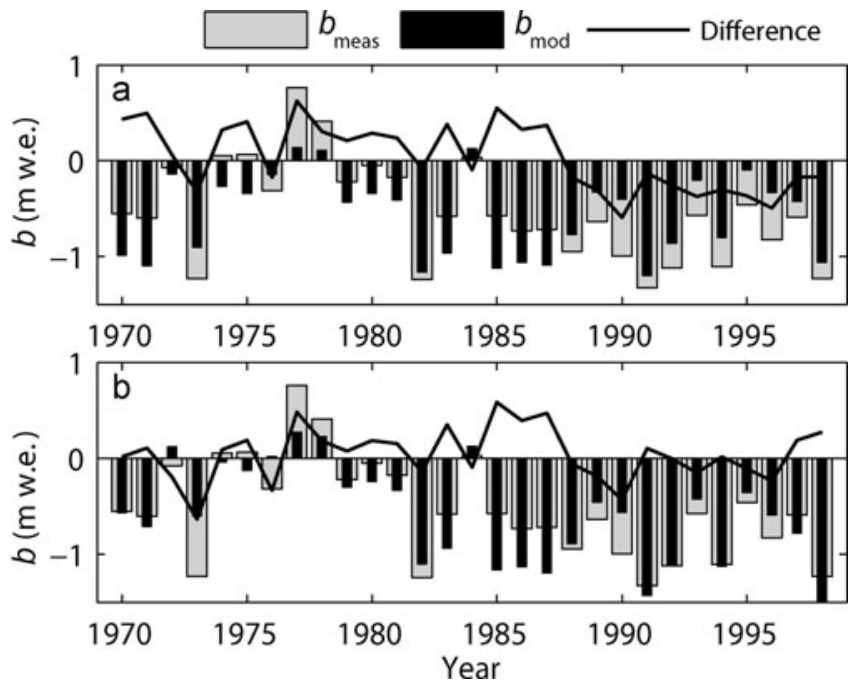

Fig. 2. Measured $\left(b_{\text {meas }}\right)$ and modelled mean specific surface mass balance $\left(b_{\text {mod }}\right)$ at HEF for two different model runs. (a) is calculated with constant DDFs over time; in (b), a temporally rising DDF value is introduced based on findings of Figure 3.

validation data (i.e. measured mass balance) exist. Figure $2 \mathrm{a}$ shows that the model approximates the pattern of glacier change. There is a clear temporal dependence of the differences between measured and modelled balance. Until about 1987, measured balances are more positive than modelled balances; after 1987, this trend is reversed.

This result is investigated further by asking: which annual values do DDFs have to have averaged over an ablation season to reproduce the measured mass balance of each year on the four glaciers with continuous mass-balance data? This is shown in Figure 3 where mean annual DDFs are plotted over time. The average DDFs are calculated as

$$
\mathrm{DDF}_{\mathrm{avg}}=\frac{B_{\mathrm{ann}, \text { meas }}-B_{\mathrm{acc}, \mathrm{mod}}}{\sum \mathrm{PDD}}\left[\mathrm{m}(\mathrm{Kd})^{-1}\right] .
$$

Figure 3 shows that there is an increase in DDFs over the observation period for all glaciers for which measured massbalance data exist: at a given temperature, more melt occurs in later than in earlier years. The increasing trend is statistically significant and its magnitude is similar for the four glaciers with complete mass-balance data. The absolute values of mean DDFs are largest for $\mathrm{VF}$, followed closely by

Table 2. Mean absolute difference, $M D_{a b s}$, and the mean signed difference, MD, between annually measured and modelled balances, the correlation coefficient, $R$, and the standard deviation, STD, of the differences for two model runs (run I: constant DDFs; run II: temporally changing DDFs following the findings of Fig. 3) for 1969-98. $M D_{a b s}, M D$ and STD are in $m$ w.e., $R$ is dimensionless

\begin{tabular}{|c|c|c|c|c|c|c|c|c|}
\hline \multirow[t]{2}{*}{ Glacier } & \multirow[b]{2}{*}{$\mathrm{MD}_{\mathrm{abs}}$} & \multirow[b]{2}{*}{ MD } & \multicolumn{3}{|c|}{ Run I } & \multicolumn{3}{|c|}{ Run II } \\
\hline & & & $R$ & STD & $\mathrm{MD}_{\mathrm{abs}}$ & $M D$ & $R$ & STD \\
\hline HEF & 0.31 & -0.03 & 0.75 & 0.35 & 0.22 & -0.05 & 0.85 & 0.28 \\
\hline KWF & 0.33 & -0.16 & 0.70 & 0.37 & 0.30 & -0.17 & 0.80 & 0.35 \\
\hline VF & 0.34 & 0.10 & 0.60 & 0.44 & 0.28 & 0.08 & 0.75 & 0.38 \\
\hline SSK & 0.41 & 0.10 & 0.72 & 0.54 & 0.35 & 0.07 & 0.81 & 0.45 \\
\hline
\end{tabular}

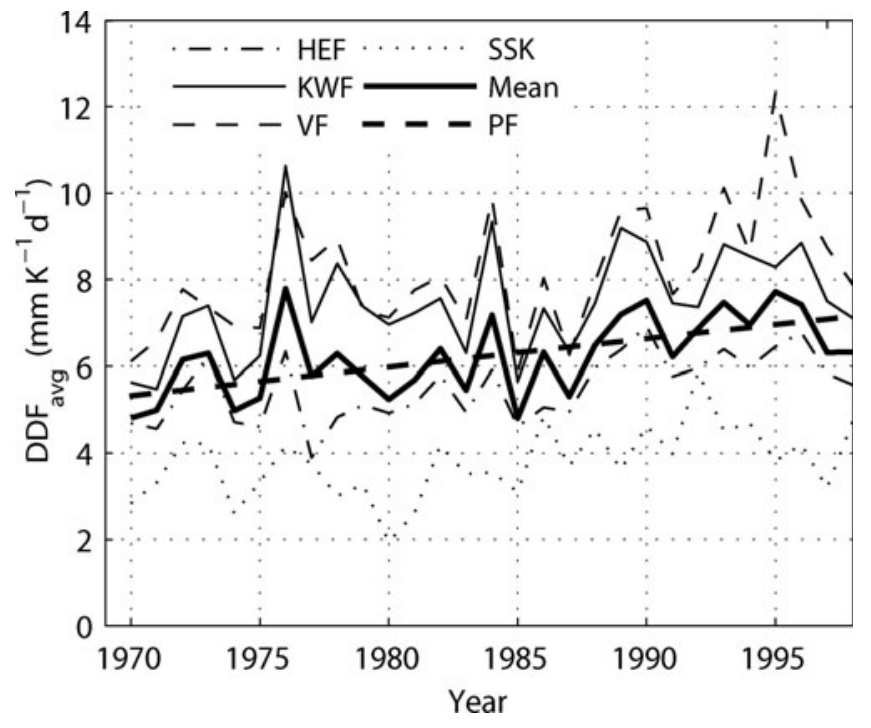

Fig. 3. Mean area- and elevation-weighted DDF that best reproduces the measured annual surface mass balance of HEF, KWF, VF and SSK and these glaciers' mean as calculated according to Equation (4). PF is the polynomial second-order fit that is calculated in order to represent the mean of the glacier's individual values.

KWF, significantly lower for HEF and lowest for SSK. For the three glaciers of the Ötztal Alps (HEF, KWF, VF), these differences are likely due to the influence of shortwave radiation. The south-facing VF and southeast-facing KWF receive more shortwave radiation than northeast-facing HEF (Table 1) and therefore have higher DDFs, a result that is consistent with previous research (e.g. Hock, 2005). SSK also provides a valuable comparison: it is located in a different climate with significantly more precipitation (Abermann and others, 2011). More precipitation may cause a higher mean albedo and thus lower mean DDFs. We calculated a secondorder polynomial fit (PF) that best represents the mean of all DDF increases, and found that the overall increase is $\sim 1.5 \mathrm{~mm}(\mathrm{Kd})^{-1}$ over the 29 years observed.

In the second model run (run II), we introduce a time dependence of DDF for each glacier. The best-fitting set of DDFs as found in run I is altered with time by the rate determined by the polynomial increase according to Figure 3. This altered DDF $\left(\mathrm{DDF}_{\text {II }}\right)$ at any point in time of the study period (dates), which has to be inserted as a serial date number with 0 at 1 January 0000, increasing by 1 each day (amounting for example to 719529 for 1 January 1970), can be expressed by the best-fitting DDF as determined in run I $\left(\mathrm{DDF}_{1}\right)$ :

$$
\begin{aligned}
\mathrm{DDF}_{\|}\left(\text {date }_{\mathrm{s}}\right)=\mathrm{DDF}_{\mathrm{I}} & -\left(3.306 \times 10^{-13}\right) \text { date }_{\mathrm{s}}^{2} \\
+ & \left(6.439 \times 10^{-7}\right) \text { date }_{\mathrm{s}}-0.2930 .
\end{aligned}
$$

DDF is now a four-dimensional (3-D: run I; 4-D: run II) function of space and time. Figure $2 \mathrm{~b}$ shows modelled balances with temporally varying DDFs and measured balances for HEF, as well as their differences. Both the trend and the annual values are better modelled than in the previous run. This is also shown in Table 2 in the mean absolute differences $\left(M D_{a b s}\right)$, mean signed differences $(M D)$, standard deviations (STD) of the differences between measured and modelled balances and the correlation coefficients, $R$, between measured and modelled balances. Without exception, the second run gave better results: 


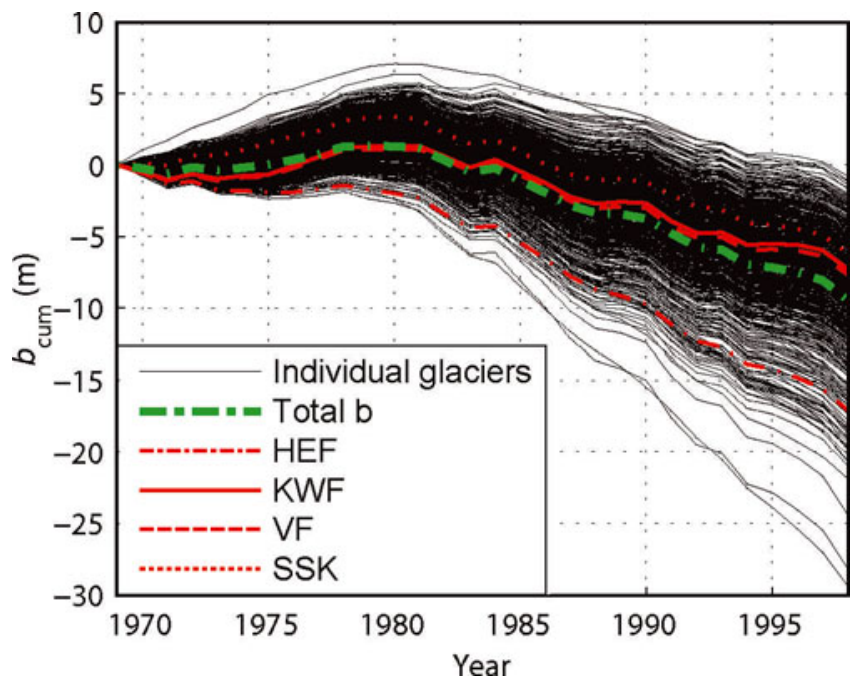

Fig. 4. Cumulative mean specific surface mass balance of all modelled glaciers in Austria (black lines) individually; the green line shows their total cumulative mean specific mass balance. The red lines show modelled balances of the glaciers where direct massbalance measurements exist.

smaller $\mathrm{MD}_{\mathrm{abs}}, \mathrm{MD}$ and $\mathrm{STD}$, and larger $R$. The MD values, small in all cases but largest for KWF $(0.17 \mathrm{~m}$ w.e.), suggest that errors largely compensate each other. The correlation coefficients between measured and modelled balance are similar for the four glaciers with directly measured data: they are highest for HEF (0.85) and lowest for VF (0.75) and on average 0.81 . The performance of the model using a linear fit versus a second-order polynomial fit is compared: on average the second-order polynomial fit produces slightly higher correlation coefficients, which is why it is used for the final result.

The results of run II are shown in Figure 4 for all Austrian glaciers for which two DEMs exist (761 out of 900 glaciers; 451 out of $470 \mathrm{~km}^{2}$, i.e. $96 \%$ of the total glacier area). The evolution of modelled cumulative annual $b$ with time is shown (each black line corresponds to one glacier). In total, $9.4 \mathrm{mw}$.e. on the ice-covered area of $451 \mathrm{~km}^{2}$ was lost between 1969 and 1998, which amounts to $4.7 \mathrm{~km}^{3}$ w.e. The wide spread of the curves is due to differences in glacier type and to the individual glacier's deviation from steady state. The red curves show the cumulative modelled $b$ of the glaciers with directly measured mass balance, and the total, area-weighted cumulative mean specific mass balance is computed and displayed as a green line. Initially, the glaciers' masses remained constant. Starting in 1975, all glaciers show a period of positive mass balances, with a total gain of $\sim 1.3 \mathrm{~m}$ w.e., corresponding to an ice volume gain of $\sim 1 \mathrm{~km}^{3}$. Since 1980, only a few years (e.g. 1984 and 1989) interrupt the generally negative trend. This temporal sequence is in agreement with the cumulative volume change derived from direct surface mass-balance measurements as compiled, for example, in Abermann and others (2009).

In Figure 5 the set of DDFs that best reproduced the observed glacier mass loss, the glacier's median elevation (location of the circles) and the mean winter precipitation at the glacier (colours) are displayed. Each thin line represents the $\operatorname{DDF}(z)$ of the run with temporally constant DDFs. There is a clear relationship between the median elevation and the DDF at this elevation. The higher the median elevation, the more melt generally occurs at a given temperature and

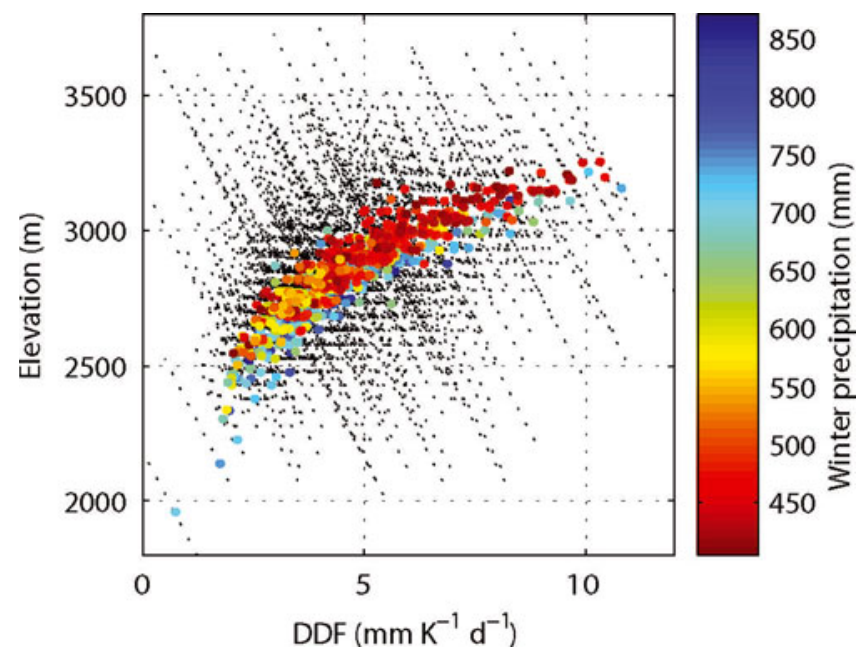

Fig. 5. DDF as a function of elevation for each glacier (thin dashed lines). The colour of the dots shows the mean winter precipitation at the glacier's coordinate according to HISTALP (October-May, colour scale); their location is determined by the DDF at the glacier's median elevation (left and bottom scale).

given precipitation. There are two possible explanations for this apparent paradox. First, glaciers usually exist at low median elevations (below $2700 \mathrm{ma}$ a.s.I.) because they generally accumulate more mass in winter than glaciers with high median elevations do. This is evident in Figure 5, where glaciers with low median elevations show greater precipitation values (blue to yellow colours). However, more wind drift, more avalanching or some combination of these factors can give an additional mass input. As a result, ice is kept under snow cover for a longer part of the ablation season, so the albedo is comparatively high. Second, increasing shortwave radiation with elevation due to less shading and fewer aerosols results in higher general DDF values at higher elevations, as suggested by Lang and Braun (1990) and Hock (2003).

\section{DISCUSSION}

The dependence of DDF with time is a major challenge when attempting to model future glacier change. For example, consider the problem faced by a hypothetical modeller in 1975 who sought to model future glacier mass balance through 1998 using mass-balance records from Figure 2 since 1969. He could not have known the future time dependence of DDF, and any reasonable assumption would have resulted in a significant underestimation of ice loss, as is obvious from Figure 2.

The subject of temporally changing DDFs was addressed by Huss and others (2009) who found a decrease in DDFs of $\sim 7 \%$ per decade between 1970 and 2008. This seems to contradict the findings of this study but can be explained by the fact that Huss and others (2009) calculated point mass balance, and thus DDFs at point locations that are all in the accumulation area. The increase in DDFs in our study amounts to $\sim 9 \%$ per decade and must be understood as a collective signal for an entire glacier. Since mass balances in recent years have been governed by ablation, it is the ablation area that controls recent glacier-averaged DDF changes. A probable explanation of the glacier-averaged DDF increase could be the increased duration of bare-ice 
exposure and thus a lower mean surface albedo in later years of the study period. Furthermore, two recent studies show that ice albedo recently decreased significantly as a result of additional dust accumulation after a sequence of negative mass-balance years (Oerlemans and others, 2009; Fischer, 2010). The recent accelerated glacier retreat may be partly due to this.

An additional explanation for the temporal increase of the DDFs could be found by considering changes of glacier flow velocities in recent years. Less mass accumulated in upper parts of a glacier leads to less mass turnover and thus less ice supply for the glacier tongues. A strong velocity decrease has been found by exploiting long-term velocity measurements on HEF (Span and others, 1997) and KWF (Abermann and others, 2007). Which of these three processes (albedo, decreased mass transport and dynamical thinning) is the strongest component is beyond the scope of this study. A more process-based approach to separate components of the energy balance, combined with a dynamical ice-flow model, is needed.

This study has several simplifications: The fraction of volume change that is a result of basal melt is not accounted for. This volume loss is reflected in measured volume changes but not in the modelled surface balance as too little is known about its magnitude to accurately model it. Locally, this may be an important contribution to a glacier's mass loss, but on average, and compared to the large surface mass loss, basal melt can be assumed to be negligible (Hooke, 2005).

Another simplification is the assumption that all volume was lost as ice. Several aerial photographs were examined qualitatively, indicating that a fraction of the lost volume was snow. For a study of this scale, however, it is not possible to attribute a proportion of volume that was lost as snow to each glacier. Therefore, to estimate the possible impact on the results, the model was run with the exaggerated assumption that half of the lost volume was snow with a density of $550 \mathrm{~kg} \mathrm{~m}^{-3}$. The resulting total volume loss then amounts to $3.87 \mathrm{~km}^{3}$ w.e. or $9 \%$ less than calculated with ice density only (i.e. $4.74 \mathrm{~km}^{3}$ w.e. loss). The pattern of the cumulative mass balance as well as the modifications of DDF as a function of time and space do not change considerably, so the results would be altered quantitatively but not qualitatively.

The sensitivity of the tuning parameters to the result of this study was investigated by altering them stepwise and comparing the difference between the altered and the best-fitting (run II) mean annual balances. If the DDF is increased systematically by $1 \mathrm{~mm} \mathrm{~K}^{-1} \mathrm{~d}^{-1}$, mean annual balances for all modelled glaciers become more negative by $600 \mathrm{~mm}$ w.e. Likewise, the sensitivity of the vertical gradient of the DDFs (i.e. steepening or flattening the slope of the black lines in Fig. 5) is investigated. Model results are not sensitive to changes in DDF gradients: Changing the vertical dependence of DDF from $-0.32 \mathrm{~mm}^{-1}(\mathrm{Kd})^{-1}(100 \mathrm{~m})^{-1}$ to $-0.20 \mathrm{~mm}(\mathrm{Kd})^{-1}(100 \mathrm{~m})^{-1}$ (i.e. steepening the slope with zero change at the glacier's median elevation) leads to a reduction of mean annual $b$ by $4 \mathrm{~mm}$. Flattening the slope with zero change at the glacier's median elevation (i.e. -0.44 $\left.\mathrm{mm}(\mathrm{Kd})^{-1}(100 \mathrm{~m})^{-1}\right)$ leads to a reduction of mean annual $b$ by $9 \mathrm{~mm}$.

The data presented in this study allow for an estimation of the relative importance of the main climatic parameters that govern annual glacier mass balances. In Table 3 we
Table 3. Correlation coefficients of the four variables' anomalies (winter (October-May) ( $\left.\delta P_{\text {winter }}\right)$ and summer (June-August) precipitation $\left(\delta P_{\text {summer }}\right)$ and annual $\left(\delta \Sigma \mathrm{PDD}_{\text {year }}\right)$ and summer $\left(\delta \Sigma \mathrm{PDD}_{\text {summer }}\right)$ PDD sums) with measured balances. Bold numbers indicate statistical significance at the $99 \%$ confidence level

\begin{tabular}{lrrrr}
\hline & HEF & VF & KWF & \multicolumn{1}{c}{ SSK } \\
\hline$\delta P_{\text {winter }}$ & 0.36 & 0.18 & 0.07 & 0.12 \\
$\delta P_{\text {summer }}$ & 0.11 & 0.20 & 0.13 & 0.39 \\
$\delta \Sigma$ PDD $_{\text {year }}$ & $\mathbf{- 0 . 6 6}$ & $\mathbf{- 0 . 6 6}$ & $\mathbf{- 0 . 5 9}$ & $\mathbf{- 0 . 7 1}$ \\
$\delta \Sigma$ PDD $_{\text {summer }}$ & $\mathbf{- 0 . 7 2}$ & $\mathbf{- 0 . 6 9}$ & $\mathbf{- 0 . 7 4}$ & $\mathbf{- 0 . 7 8}$ \\
\hline
\end{tabular}

summarize correlation coefficients between measured balances of the four well-studied glaciers and anomalies of PDD sums for the whole year, PDD sums for the summer (June-August), winter precipitation (October-May) and summer precipitation, all of which are interpolated to the glacier's gridpoint. Deviations of winter and summer precipitation correlate only weakly with the measured balance. Annual anomalies of PDD sums correlate much more strongly with surface mass balance than precipitation anomalies do. The strongest correlation between meteorological data and measured balances is found between summer anomalies of PDD sums and the measured balance $b$ (between -0.71 and -0.74 ), which is consistent with the results of Kuhn and others (1999), who examined this for HEF. All four glaciers have similar correlation values, but SSK shows a significantly higher correlation between summer precipitation anomalies and $b$ than the other glaciers, and HEF's balance is more sensitive than those of the other glaciers to winter precipitation.

The results presented in Figure 4 can be taken as an indication of the generalizability of measured mass balances to all Austrian glaciers modelled in this study. HEF has a much more negative mass balance than most other glaciers, so its $b$ is not representative for the overall mass balance of all Austrian glaciers. The specific balances of VF and KWF are close to the average, while SSK's mean specific balance is more positive than the average.

\section{CONCLUSIONS}

The change over time in the mean annual surface mass balance of all Austrian glaciers for which two DEMs exist between 1969 and 1998 has been investigated in this study. With a PDD model with DDFs that vary in space (3-D) and time, correlation coefficients of $>0.8$ on average between measured and modelled balances for the four glaciers with direct measurements for validation are reached. Tuning parameters have to be calibrated to each glacier individually to reach a satisfying result. A relation is found between the glacier's median elevation, mean winter precipitation and the DDF. The general increase in DDFs with time is likely to be due to a larger fraction of the glacier surface that exposes bare ice for an increasingly longer part of the summer, and thus a lower mean albedo. This is consistent with a sequence of negative balance years and an increase in equilibriumline altitude. Calibrating a PDD model with only a few years of measurements and then extrapolating to the past or future seems extremely unreliable without additional knowledge (e.g. DEMs at various points in time). There are ongoing 
efforts to extend this study further towards the present and include a new glacier inventory of 2006 (Abermann and others, 2009) in order to investigate how these parameters have evolved in the very recent past. This model could also be used to reproduce mass balances back to the Little Ice Age glacier maximum, for which information on extent and surface elevation could be reconstructed from locations of moraines, thus providing a fascinating picture of $>150$ years of glacier history.

\section{ACKNOWLEDGEMENTS}

This study was funded by the Commission for Geophysical Research, Austrian Academy of Sciences. We thank the Institute of Meteorology and Geophysics, Innsbruck, the Bavarian Academy of Sciences, Munich, Germany, and H. Slupetzky for providing mass-balance data. The ECMWF/ ERA-40 reanalysis project and the HISTALP database provided the meteorological data. We thank E. Dreiseitl, E. Schlosser, L.A. Rasmussen and S. Kinter for comments and proofreading. Two anonymous reviewers and the editor are acknowledged for helpful suggestions.

\section{REFERENCES}

Abermann, J., H. Schneider and A. Lambrecht. 2007. Analysis of surface elevation changes on Kesselwand glacier - comparison of different methods. Z. Gletscherkd. Glazialgeol., 41, 147-167.

Abermann, J., A. Lambrecht, A. Fischer and M. Kuhn. 2009. Quantifying changes and trends in the glacier area and volume in the Austrian Ötztal Alps (1969-1997-2006). Cryosphere, 3(2), 205-215.

Abermann, J., M. Kuhn and A. Fischer. 2011. Climatic controls of glacier distribution and glacier changes in Austria. Ann. Glaciol., 52(59) (see paper in this issue).

Auer, I. and 23 others. 2005. A new instrumental precipitation dataset for the greater alpine region for the period 1800-2002. Int. J. Climatol., 25(2), 139-166.

Böhm, R., I. Auer, M. Granekind and A. Orlik. 2008. Zwei Jahrhunderte Klimaschwankungen in zwei Tälern der Zentralalpen. Jahrb. Sonnblick-Ver.

Braithwaite, R.J. 2002. Glacier mass balance: the first 50 years of international monitoring. Progr. Phys. Geogr., 26(1), 76-95.

Dyurgerov, M.B. and M.F. Meier. 2005. Glaciers and the changing Earth system: a 2004 snapshot. Boulder, CO, University of Colorado. Institute of Arctic and Alpine Research. (INSTAAR Occasional Paper 58.)

Efthymiadis, D. and 7 others. 2006. Construction of a 10-mingridded precipitation data set for the Greater Alpine Region for 1800-2003. J. Geophys. Res., 111(D1), D01105. (10.1029/ 2005JD006120.)

Escher-Vetter, H., M. Kuhn and M. Weber. 2009. Four decades of winter mass balance of Vernagtferner and Hintereisferner, Austria: methodology and results. Ann. Glaciol., 50(50), 87-95.

Fischer, A. 2010. Glaciers and climate change: interpretation of 50 years of direct mass balance of Hintereisferner. Global Planet. Change, 71(1-2), 13-26.

Fischer, A. and G. Markl. 2008. Mass balance measurements on Hintereisferner, Kesselwandferner and Jamtalferner 2003 to 2006. Database and results. Z. Gletscherkd. Glazialgeol., 42(1), 47-83

Fountain, A.G., M.J. Hoffman, F. Granshaw and J. Riedel. 2009. The 'benchmark glacier' concept - does it work? Lessons from the North Cascade Range, USA. Ann. Glaciol., 50(50), 163-168.

Frei, C. and C. Schär. 1998. A precipitation climatology of the Alps from high-resolution rain-gauge observations. Int. J. Climatol., 18(8), 873-900.
Greuell, J.W. and T. Konzelmann. 1994. Numerical modeling of the energy balance and the englacial temperature of the Greenland ice sheet: calculations for the ETH-Camp location (West Greenland, 1155 m a.s.I.). Global Planet. Change, 9(1-2), 91-114.

Gross, G. 1987. Der Flächenverlust der Gletscher in Österreich 1850-1920-1969. Z. Gletscherkd. Glazialgeol., 23(2), 131-141.

Hock, R. 2003. Temperature index melt modelling in mountain areas. J. Hydrol., 282(1-4), 104-115.

Hock, R. 2005. Glacier melt: a review on processes and their modelling. Progr. Phys. Geogr., 29(3), 362-391.

Hock, R., M. de Woul and V. Radić. 2009. Mountain glaciers and ice caps around Antarctica make a large sea-level rise contribution. Geophys. Res. Lett., 36(7), L07501. (10.1029/ 2008GL037020.)

Hoinkes, H. and H. Lang. 1962. Der Massenhaushalt von Hintereisund Kesselwandferner (Ötztaler Alpen), 1957/58 und 1958/59. Arch. Meteorol. Geophys. Bioklimatol., Ser. B., 12(1), 284-320.

Hooke, R.LeB. 2005. Principles of glacier mechanics. Second edition. Cambridge, etc., Cambridge University Press.

Huss, M., A. Bauder, M. Funk and R. Hock. 2008. Determination of the seasonal mass balance of four Alpine glaciers since 1865. J. Geophys. Res., 113(F1), F01015. (10.1029/2007JF000803.)

Huss, M., M. Funk and A. Ohmura. 2009. Strong Alpine glacier melt in the 1940s due to enhanced solar radiation. Geophys. Res. Lett., 36(23), L23501. (10.1029/2009GL040789.)

Kaser, G., J.G. Cogley, M.B. Dyurgerov, M.F. Meier and A. Ohmura. 2006. Mass balance of glaciers and ice caps: consensus estimates for 1961-2004. Geophys. Res. Lett., 33(19), L19501. (10.1029/2006GL027511.)

Kuhn, M. 2003. Redistribution of snow and glacier mass balance from a hydrometeorological model. J. Hydrol., 282(1-4), 95-103.

Kuhn, M., U. Nickus and F. Pellet. 1982. Die Niederschlagsverhältnisse im inneren Ötztal. In 17. Internationale Tagung für Alpine Meteorologie, 21.-25. September 1982, Berchtesgaden. Offenbach am Main, Deutscher Wetterdienst, 235-237.

Kuhn, M., G. Markl, G. Kaser, U. Nickus, F. Obleitner and H. Schneider. 1985. Fluctuations of climate and mass balance: different responses of two adjacent glaciers. Z. Gletscherkd. Glazialgeol., 21(1-2), 409-416.

Kuhn, M., E. Dreiseitl, S. Hofinger, G. Markl, N. Span and G. Kaser. 1999. Measurements and models of the mass balance of Hintereisferner. Geogr. Ann., 81A(4), 659-670.

Kuhn, M., A. Lambrecht, J. Abermann, G. Patzelt and G. Gross. 2009. Die österreichischen Gletscher 1998 und 1969, Flächenund Volumenänderungen. Wien, Österreichische Akademie der Wissenschaften. (Landesverteidigungsakademie, Bundesministerium für Landesverteidigung Projektbericht 10.)

Lambrecht, A. and M. Kuhn. 2007. Glacier changes in the Austrian Alps during the last three decades, derived from the new Austrian glacier inventory. Ann. Glaciol., 46, 177-184.

Lang, H. and L. Braun. 1990. On the information content of air temperature in the context of snow melt estimation. IAHS Publ. 190 (Symposium at Strbské Pleso 1988 - Hydrology of Mountainous Areas), 347-354.

Lemke, P. and 10 others. 2007. Observations: changes in snow, ice and frozen ground. In Solomon, S. and 7 others, eds. Climate change 2007: the physical science basis. Contribution of Working Group I to the Fourth Assessment Report of the Intergovernmental Panel on Climate Change. Cambridge, etc., Cambridge University Press, 339-383.

Machguth, H., F. Paul, S. Kotlarski and M. Hoelzle. 2009. Calculating distributed glacier mass balance for the Swiss Alps from regional climate model output: a methodical description and interpretation of the results. J. Geophys. Res., 114(D19), D19106. (10.1029/2009JD011775.)

Meier, M.F. and 7 others. 2007. Glaciers dominate eustatic sealevel rise in the 21st century. Science, 317(5841), 1064-1067. 
Oerlemans, J., R.H. Giesen and M.R. van den Broeke. 2009. Retreating alpine glaciers: increased melt rates due to accumulation of dust (Vadret da Morterastch, Switzerland). J. Glaciol., 55(192), 729-736.

Radić, V. and R. Hock. 2006. Modeling future glacier mass balance and volume changes using ERA-40 reanalysis and climate models: sensitivity study at Storglaciären, Sweden. J. Geophys. Res., 111(F3), F03003. (10.1029/2005JF000440.)

Rasmussen, L.A. and J.M. Wenger. 2009. Upper-air model of summer balance on Mount Rainier, USA. J. Glaciol., 55(192), 619-624.

Reinwarth, O. and H. Escher-Vetter. 1999. Mass balance of Vernagtferner, Austria, from 1964/65 to 1996/97: results for three sections and the entire glacier. Geogr. Ann., 81A(4), 743-751.

Schöner, W. and R. Böhm. 2007. A statistical mass-balance model for reconstruction of LIA ice mass for glaciers in the European Alps. Ann. Glaciol., 46, 161-169.

Schrott, D. 2006. Flächenhafte Modellierung der Energie- und Massenbilanz am Hintereisferner. (Diplomarbeit, Universität Innsbruck.)
Slupetzky, H. 1989. Die Massenbilanzmessreihe vom Stubacher Sonnblickkees 1958/59 bis 1987/88 - Die Berechnung der Massenbilanz $1980 / 81$ bis $1987 / 88$ und $1958 / 59$ bis $1962 / 63$. Z. Gletscherkd. Glazialgeol., 25(1), 69-89.

Slupetzky, H. 2003. Do we need long term terrestrial glacier mass balance monitoring for the future? Geophys. Res. Abstr., 5, EAE03-A-11390.

Span, N., M. Kuhn and H. Schneider. 1997. 100 years of ice dynamics of Hintereisferner, central Alps, Austria, 1894-1994. Ann. Glaciol., 24, 297-302.

Steinacker, R. 1983. Diagnose und Prognose der Schneefallgrenze. Wetter Leben, 35, 81-90.

Stull, R. 2000. Meteorology for scientists and engineers. Second edition. Forest Grove, CA, Brooks/Cole.

Uppala, S.M. and 45 others. 2005. The ERA-40 re-analysis. Q. J. $R$. Meteorol. Soc., 131(612), 2961-3012.

World Glacier Monitoring Service (WGMS). 2007. Glacier Mass Balance Bulletin No. 9 (2004-2005), ed. Haeberli, W., M. Zemp and M. Hoelzle. ICSU (FAGS)/IUGG (IACS)/UNEP/UNESCO/ WMO, World Glacier Monitoring Service, Zürich. 